\title{
Tautomerism in 1-phenylazo-4-naphthols: Experimental results vs quantum-chemical predictions
}

\author{
Liudmil Antonov $^{\mathrm{a}, *}$, Vanya Kurteva ${ }^{\mathrm{a}}$, Aurelien Crochet $^{\mathrm{b}}$, Laurent Mirolo ${ }^{\mathrm{b}}$, \\ Katharina M. Fromm ${ }^{\text {b }}$, Silvia Angelova ${ }^{\text {a }}$ \\ a Institute of Organic Chemistry with Centre of Phytochemistry, Bulgarian Academy of Sciences, Acad. G. Bonchev Str., Bl.9, Sofia 1113, Bulgaria \\ ${ }^{\mathrm{b}}$ University of Fribourg, Department of Chemistry, Chemin du Musée 9, CH-1700 Fribourg, Switzerland
}

\section{Introduction}

Quantum-chemical calculations are a very suitable tool to study the tautomeric compounds, but the results always remain captive on the level of theory and basis set used [1,2]. This is especially true for the description of systems, where the tautomers co-exist in solution. In order to create a solid base for theoretical investigation of the proton transfer mechanism and the effects of the environment quantum chemists need for a start to have correct description of the stationary keto/enol tautomeric ratio.

The tautomerism in 1-phenylazo-4-naphthol (1, Scheme 1$)$ is one of the first discovered more than 120 years ago in a pure chemical manner [3]. It is well known that in solution $\mathbf{1}$ always exists as keto-enol tautomeric mixture and the tautomeric ratio (quantitatively defined as a tautomeric constant $K_{\mathrm{T}}, K_{\mathrm{T}}=[K] /[E]$ ), is very sensitive to the solvent environment and the temperature $[4,5]$. In spite of the intensive spectral and theoretical investigations many questions about the effects influencing the tautomerism in azonaphthols remained unanswered, due to the impossibility to isolate the individual tautomers by switching of the equilibrium $[6,7]$.

\footnotetext{
* Corresponding author. Fax: +3592 8700225 .

E-mail address: lantonov@orgchm.bas.bg (L. Antonov).
}

Only recently advanced chemometric tools for processing of spectra of tautomeric mixtures have been developed and used to study in exact, quantitative, manner the tautomerism in $\mathbf{1}$ and in related azonaphthols and Schiff bases [6,8]. This has created conditions for exact estimation of the thermodynamic parameters governing the equilibrium (entropy, enthalpy, free energy) in nonpolar solvents, ${ }^{1}$ which gives a chance for direct comparison with the quantum-chemical results avoiding the complications of theoretical description of the specific solvent effects [1,9]. Such data give unique opportunity to test the theoretical results and to look for conditions (level of theory/basis set) that correctly describe the tautomerism in $\mathbf{1}$ as a first step for finding acceptable general solution for this class of dyes.

In addition, again recently, structural conditions for controlled shift of the tautomeric equilibrium in $\mathbf{1}$ were created [10]. In compounds $\mathbf{2}$ and $\mathbf{3}$ due to the intramolecular hydrogen bonding the equilibrium is fully shifted toward the enol form and under protonation can be gradually shifted to the keto tautomer. In such

\footnotetext{
${ }^{1}$ In the following discussion under non-polar solvents we understand solvents with low polarity and without abilities for specific (proton donor/proton acceptor) interactions with the individual tautomers. This means for instance that the chloroform is excluded from this category.
} 

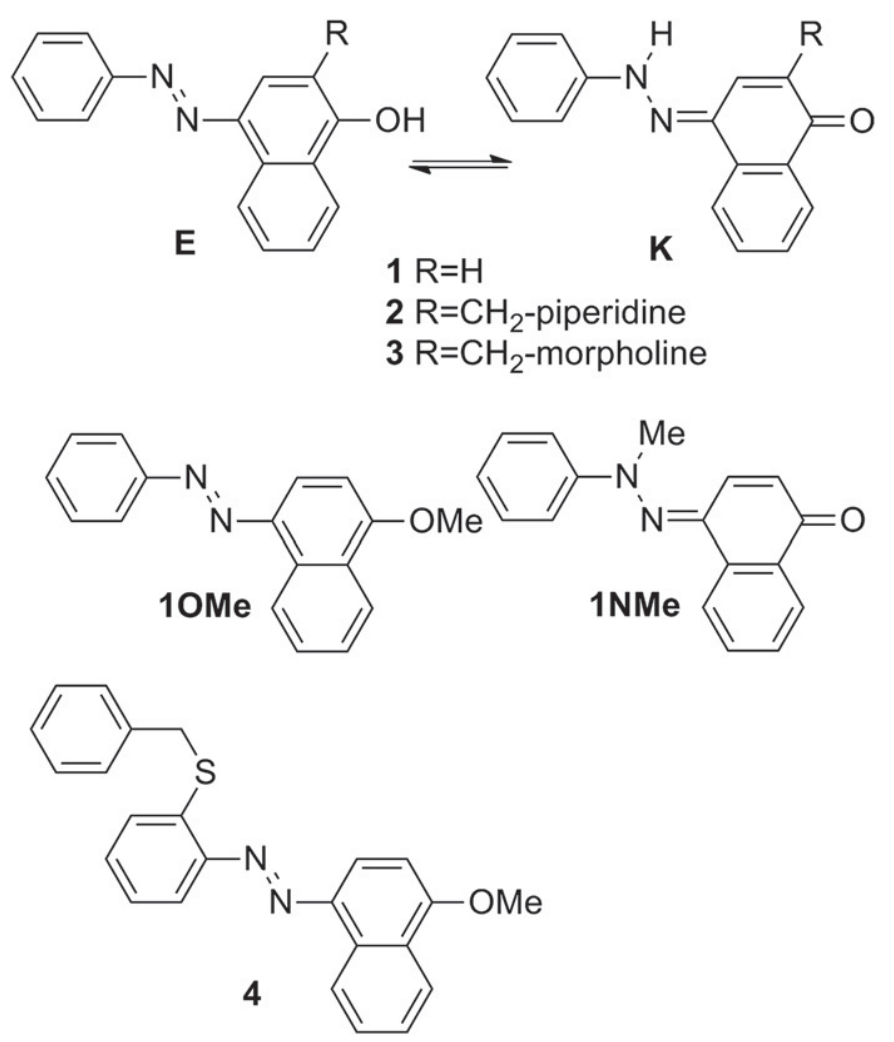

Scheme 1. Compounds under investigation.

a case the individual tautomers have been obtained for the first time in solution. The next step is to isolate them in solid state and to use the crystal structures as an additional opportunity to test the quantum chemical results.

In the current communication we report the crystal structures of the pure enol form of $\mathbf{1}$ obtained by structural modifications ( $\mathbf{2}$ and 3) and the crystal structures of the so-called model tautomers (10Me and 1NMe), where the tautomeric proton is replaced by a methyl group. It is first time when structural information for the individual tautomers of $\mathbf{1}$ is provided and this information, along with the data available in the literature for $\mathbf{4}$ [11] will be used to estimate the reliability of the individual tautomeric structures optimized by the quantum chemical calculations at various levels of theory and basis sets. In addition we will use a set of experimentally obtained tautomeric constants at room temperature in non-polar solvents in order to evaluate the theoretical predictions of the relative stabilities of the keto and enol tautomers. Although there are theoretical studies dealing with the relative stabilities of the tautomers of $\mathbf{1}$ [12], such a comprehensive study has not been performed yet. In this respect two facts have to be taken into account - the compound $\mathbf{1}$ is of size that limits the use of very sophisticated quantum-chemical methods and the lack of intramolecular hydrogen bonding ${ }^{2}$ in the individual tautomers $(\mathbf{1 E}$ and 1K) makes this tautomeric system well defined in respect to position of the tautomeric proton and less complicated in the theoretical description of the individual tautomers.

The current work represents the extensive test of various methods (including DFT ones) for prediction of the geometry and the relative stabilities of tautomers in the studied compound. The

\footnotetext{
${ }^{2}$ As it exists in the azonaphthols and Schiff bases derived from 2-naphthol for instance.
}

results from the DFT calculations are extremely important due to the fact that on one side DFT methods being computationally inexpensive are very attractive, but on the other side, sometimes fail even for seemingly simple systems, as shown by Grimme [13].

However, taking into account the fact that the study is performed for one compound only, the purpose of the current communication is not to provide general answers about the most suitable level of theory and basis sets, but to initiate a discussion and to be used as a guide for further studies of larger sets of tautomeric compounds.

\section{Experimental part}

\subsection{Synthesis}

\subsubsection{General}

All reagents were purchased from Aldrich, Merck and Fluka and were used without any further purification. Fluka silica gel/TLC-cards 60778 with fluorescent indicator $254 \mathrm{~nm}$ were used for TLC chromatography and $\mathrm{R}_{\mathrm{f}}$-values determination. The purifications were carried out on a Biotage Horizon TM HPFC system (Charlottesville, Virginia, USA) on silica gel. The melting points were determined in capillary tubes on SRS MPA100 OptiMelt (Sunnyvale, CA, USA) automated melting point system. The NMR spectra were recorded on a Bruker Avance II+ 600 spectrometer (Rheinstetten, Germany) in deuterochloroform; the chemical shifts were quoted in ppm in $\delta$-values against tetramethylsilane (TMS) as an internal standard and the coupling constants were calculated in $\mathrm{Hz}$. The signals for the morpholine ring protons in $\mathbf{3}$ are broadened due to a slow exchange.

Compounds 1 and 2 [10], and 10Me and 1NMe [14] were synthesized as described in the literature. Compound $\mathbf{3}$ was obtained from naphthalen-1-ol by applying diazo coupling/Mannich reaction sequence as a one-pot two step protocol without purification of the intermediately formed $\mathbf{1}$ as follows:

To aniline ( $3 \mathrm{mmol})$ ice, conc. $\mathrm{HCl}(0.9 \mathrm{ml})$, and a solution of $\mathrm{NaNO}_{2}$ (3.3 mmol) in $\mathrm{H}_{2} \mathrm{O}(8 \mathrm{ml}$ ) were subsequently added and the mixture was stirred at $0{ }^{\circ} \mathrm{C}$ for $5 \mathrm{~min}$ to form a diazonium salt. To a solution of naphthalene-1-ol (3 mmol) in acetone $(20 \mathrm{ml})$ 10\% aq. $\mathrm{NaOH}(3 \mathrm{ml})$ and then the solution of the diazonium salt were subsequently added at $0{ }^{\circ} \mathrm{C}$. The residue formed was filtered off, washed with small portions of acetone, and dried in air to give the crude $\mathbf{1}$ [3].

To a solution of morpholine $(3.3 \mathrm{mmol})$ in benzene $(20 \mathrm{ml})$ paraformaldehyde (3.3 mmol), $p$-toluenesulfonic acid $(20 \mathrm{mg}$ ), and then crude 1 ( $3 \mathrm{mmol}$ ) were added and the mixture was refluxed with stirring for $3 \mathrm{~h}$. The products were partitioned between benzene and deionized water. The organic phase was dried over $\mathrm{Na}_{2} \mathrm{SO}_{4}$, and evaporated to dryness. Purification by HPFC on silica gel by using a mobile phase with a gradient of polarity from hexane to ether:hexane 50:50, yielded 4-(Phenyldiazenyl)-2-(morpholin1-ylmethyl)naphthalen-1-ol (3) in 49\% overall yield: orange crystals, m.p. $158-159{ }^{\circ} \mathrm{C}$ (lit. $197-199{ }^{\circ} \mathrm{C}$ [15], protonated form); $R_{\mathrm{f}^{-}} 0.56$ (EtOAc:hexane 1:1); ${ }^{1} \mathrm{H}$ NMR 2.662 (bs, $4 \mathrm{H}, \mathrm{CH}_{2}-\mathrm{N}$ morpholine), 3.803 (bs, $4 \mathrm{H}, \mathrm{CH}_{2}-\mathrm{O}$ morpholine), 3.935 (s, $2 \mathrm{H}, \mathrm{Ar}_{-} \mathrm{CH}_{2}-\mathrm{N}$ ), 7.447 (t, 1H, J 7.2, $\mathrm{CH}-4 \mathrm{Ph}$ ), 7.532 (t, 2H, J 7.7, $\mathrm{CH}-3$ and $\mathrm{CH}-5 \mathrm{Ph}$ ), 7.563 (t, 1H, J 7.4, 8.2, CH-7 Ar), 7.643 (t, 1H, J 7.2, 8.2, CH-8 Ar), 7.703 (s, 1H, CH-3 Ar), 7.992 (d, 2H, J 7.7, CH-2 and $\mathrm{CH}-6 \mathrm{Ph}$ ), 8.298 (d, 1H, J 8.3, CH-9 Ar), 8.945 (d, 1H, J 8.5, CH-6 Ar), 10.844 (bs, $1 \mathrm{H}, \mathrm{OH}$ ); ${ }^{13} \mathrm{C}$ NMR $52.92\left(\mathrm{CH}_{2}-\mathrm{N}\right.$ morpholine), $61.84\left(\mathrm{Ar}-\mathrm{CH}_{2}-\mathrm{N}\right), 66.73\left(\mathrm{CH}_{2}-\mathrm{O}\right.$ morpholine), 113.25 ( $\left.C_{\text {quat }}-2 \mathrm{Ar}\right), 113.28$ ( $\left.\mathrm{CH}-3 \mathrm{Ar}\right), 122.12$ (CH-9 Ar), $122.73(\mathrm{CH}-2$ and $\mathrm{CH}-6 \mathrm{Ph}), 122.99(\mathrm{CH}-6 \mathrm{Ar}), 124.86$ ( $\left.\mathrm{C}_{\text {quat }}-10 \mathrm{Ar}\right)$, 125.61 ( $\mathrm{CH}-7 \mathrm{Ar}), 127.39(\mathrm{CH}-8 \mathrm{Ar}), 129.08$ ( $\mathrm{CH}-3$ and $\mathrm{CH}-5 \mathrm{Ph})$, 130.17 ( $\mathrm{CH}-4 \mathrm{Ph}$ ), 132.58 ( $C_{\text {quat }}-5 \mathrm{Ar}$ ), 140.30 ( $C_{\text {quat }}-4 \mathrm{Ar}$ ), 153.29 $\left(C_{\text {quat }}-1 \mathrm{Ph}\right), 157.61$ ( $\left.C_{\text {quat }}-1 \mathrm{Ar}\right)$; COSY cross peaks $2.662 / 3.803$, $7.447 / 7.532,7.532 / 7.992,7.563 / 8.298,7.56 / 7.643,7.643 / 8.945$; HSQC cross peaks 2.662/52.92, 3.803/66.73, 3.935/61.84, 7.447/130.17, 
7.532/129.08, 7.563/125.61, 7.643/127.39, 7.703/113.28, 7.992/122.73, 8.298/122.12, 8.945/122.99.

\subsection{X-ray measurements}

The crystals of $\mathbf{2}-\mathbf{3}, \mathbf{1 0 M e}$ and $\mathbf{1 N M e}$ were grown by slow diffusion of hexane into chloroform solutions of pure samples.

The corresponding crystal was mounted of on a loop and all geometric and intensity data were taken from this crystal. Data collection using Mo- $K_{\alpha}$ radiation $(\lambda=0.71073 \AA)$ was performed at $150 \mathrm{~K}$ on a STOE IPDS-II diffractometer equipped with an Oxford Cryosystem open flow cryostat [16]. Absorption correction was partially integrated in the data reduction procedure [17]. The structure was solved by SIR 2004 and refined using full-matrix least-squares on $F^{2}$ with the SHELX-97 package $[18,19]$.

Crystal data of 2: monoclinic, $P 21 /$ n (No. 14), $a=6.6970(4) \AA$ $b=19.6370(16) \AA, c=14.1770(9) \AA, \beta=114.332(5)^{\circ} . \mathrm{V}=1250.49$ (14) $\AA^{3}, Z=4, d=1.255 \mathrm{Mg} \cdot \mathrm{m}^{-3}, 3160$ reflections collected, 3160 unique, $R 1=0.0434(\mathrm{I}>2 \mathrm{~s}(\mathrm{I})), w R 2=0.1118$ (all data).

Crystal data of 3: monoclinic, $P 2{ }_{1} / \mathrm{n}$ (No. 14), $a=6.4733(6) \AA$, $b=20.047(19) \AA, c=13.9242(15) \AA, \beta=99.883(8)^{\circ} . V=1779.8(3)$ $\AA^{3}, Z=4, d=1.296 \mathrm{Mg} \mathrm{m}^{-3}, 3106$ reflections collected, 3106 unique, $R 1=0.0628(I>2 s(I)), w R 2=0.0788$ (all data).

Crystal data of 10Me: monoclinic, $P 2_{1} / \mathrm{c}$ (No. 14), $a=14.9370(6)$ $\AA, \quad b=3.9540(2) \AA, c=21.9650(8) \AA, \quad \beta=90.226(3)^{\circ} . \quad V=1297.62$ (10) $\AA^{3}, Z=4, d=1.343 \mathrm{Mg} \mathrm{m}^{-3}, 2174$ reflections collected, 2174 unique, $R 1=0.0612(I>2 \mathrm{~s}(I)), w R 2=0.1824$ (all data).

Crystal data of 1NMe: orthorhombic, $P 22_{1} 22_{1}$ (No. 19), $a=7.4130$ (2) $\AA, b=11.5930(4) \AA, c=15.0170(4) \AA, V=1290.54(7) \AA^{3}, Z=4$, $d=1.350 \mathrm{Mg} \mathrm{m}^{-3}, 2264$ reflections collected, 2264 unique, $R 1=0.0691(I>2 \mathrm{~s}(I)), w R 2=0.1677$ (all data).

\subsection{Spectral UV-Vis investigations and data processing}

The tautomeric constants at $298 \mathrm{~K}$ of $\mathbf{1}$ in cyclohexane and in methylcyclohexane/toluene (1/1), which correspond to $\Delta G$ values of $1.42 \mathrm{kcal} \mathrm{mol}^{-1}$ and $1.26 \mathrm{kcal} \mathrm{mol}^{-1}$, respectively, were taken from the literature [5]. Especially for this study the tautomeric constant in i-octane was estimated according to the methodology already described in the literature [6,8]. A value of $K_{\mathrm{T}}=0.096$ was obtained, which corresponds to $\Delta G=1.38 \mathrm{kcal} \mathrm{mol}^{-1}$ at $298 \mathrm{~K}$.

\subsection{Quantum-chemical calculations}

The molecular geometries of the tautomeric forms of $\mathbf{1}$ were optimized at HF and MP2 $a b$ initio levels of theory and by using Density Functional Theory (DFT) with variety of pure GGA (OLYP), hybrid (B3LYP and B3PW91), long range corrected (LC-BLYP [20]) and double-hybrid (B2PLYP [21] and mPW2PLYP [22]) functionals. Each of these methods was systematically tested with the following basis sets: CEP31G, 6-31G, 6-31G**, 6-31+G*, 6-31++G**, 6-311++G**, cc-pVDZ, cc-pVTZ, cc-pVQZ (except at MP2, B2PLYP and mPW2PLYP), D95, D95** and D95 $++^{* *}$. Additionally, in the DFT calculations SVP, TZVP [23] and QZVP [24] basis sets were used. The optimized structures were characterized as true minima by vibrational frequency calculations. All calculations were carried out using GAUSSIAN 09 [25].

\section{Results and discussion}

\subsection{Crystal structures}

Compound 2 crystallizes in the monoclinic space group $P 2_{1} / \mathrm{n}$ $\left(N^{\circ} 14\right)$ with one molecule per asymmetric unit (Fig. 1). The piperidine part has a chair conformation with a torsion angle

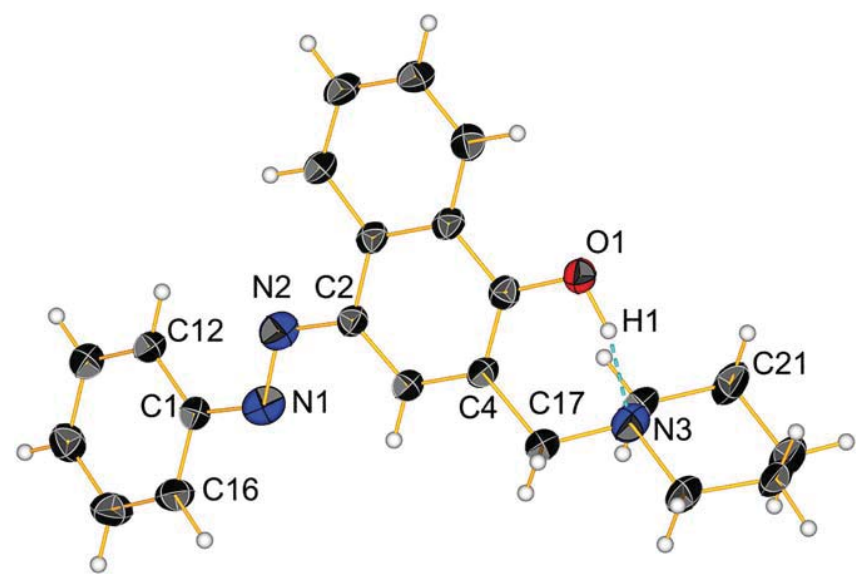

Fig. 1. View of the molecular structure of $\mathbf{2}$ with hydrogen bond indicated as dashed blue line, $50 \%$ probability. (For interpretation of the references to color in this figure legend, the reader is referred to the web version of this article).

$\mathrm{C} 20-\mathrm{C} 21-\mathrm{C} 22-\mathrm{N} 3$ of $60.2(3)^{\circ}$. $\mathrm{O} 1$ is attached to $\mathrm{C} 5$ atom from the naphthalene fragment, the bond length is $1.360(3) \AA$ and position of hydrogen atom $\mathrm{H} 1$ was determined by X-ray diffraction. This $\mathrm{H}$ atom is connected to 01 (bond length of $0.993(1) \AA$ ) and formed an intramolecular hydrogen bond of $1.786(2) \AA$ with $\mathrm{N} 3$ from the piperidine part (Table 1). The position of this $\mathrm{H}$ atom is visualized on Fourier map (Fig. 2). The molecules are arranged in zigzag shape in the crystal with an alternation of "ABA" in each layer, where "A" is molecule with $\mathrm{H}$-bonding in the direction $\mathrm{N} 3 \ldots \mathrm{H} 1-\mathrm{O} 1$ and O1-H1 ...N3 for the H-bonding of "B" (Fig. 3).

Similarly compound $\mathbf{3}$ crystallizes in the monoclinic space group $P 2_{1} / \mathrm{n}$ ( $\mathrm{N}^{\circ} 14$ ) with one molecule per asymmetric unit (Fig. S1). 01 is attached to $\mathrm{C} 5$ atom from the naphthalene fragment, the bond length is $1.348(7) \AA$ and position of hydrogen atom $\mathrm{H} 1$ was calculated, this $\mathrm{H}$ atom is visible on Fourier map (Fig. S2). This $\mathrm{H}$ atom formed an intramolecular hydrogen bond of 1.962(4) $\AA$ with N3 from the morpholine part (Table 1). The molecules are arranged in zigzag shape in the crystal with an alternation of "ABA" in each layer, where " $\mathrm{A}$ " is molecule with H-bonding in the direction N3...H1-O1 and $\mathrm{O} 1-\mathrm{H} 1 \ldots \mathrm{N} 3$ for the H-bonding of "B" (Fig. S3).

Compound 10Me crystallizes in the monoclinic space group $P 2_{1} / \mathrm{c}\left(\mathrm{N}^{\circ} 14\right)$ with one molecule per asymmetric unit (Fig. 4). The molecules are arranged in zigzag shape in the crystal with a distance of $3.5 \AA$ A between in each layer (Fig. 5).

Compound 1NMe crystallizes in the monoclinic space group $P 2{ }_{1} 2_{1} 2_{1}\left(\mathrm{~N}^{\circ} 19\right)$ with one molecule per asymmetric unit (Fig. 6). The molecules are arranged in layer (Fig. 7), two follow layer form an angle of about $11.6^{\circ}$ and two parallel layer (layer 1 and 3 for example) are distant of $7.3 \AA$.

Crystal structures of $\mathbf{2}$ and $\mathbf{3}$ clearly show that these compounds exist as enol forms stabilized via a strong hydrogen bonding [26] of the tautomeric proton with the nitrogen atom from the attached heterocycle (Table 1 ). These structures along with the data of 10Me and 4 can be used as a reference for the structure of the pure enol tautomer. Unfortunately we were not able to isolate the protonated $\mathbf{2}$ and $\mathbf{3}$ as crystals, which remains 1NMe as the only reference structure for the keto tautomer. The packing of the above discussed

Table 1

Hydrogen bonds in the fragment $\mathrm{O} 1-\mathrm{H} 1 \cdots \mathrm{N} 3$ for $\mathbf{2}$ and $\mathbf{3}\left[\AA \AA\right.$ and $\left.{ }^{\circ}\right]$.

\begin{tabular}{lllll}
\hline Compound & $\mathrm{d}(\mathrm{O}-\mathrm{H})$ & $\mathrm{d}(\mathrm{H} \cdots \mathrm{N})$ & $\mathrm{d}(\mathrm{O} \cdots \mathrm{N})$ & $<(\mathrm{OHN})$ \\
\hline $\mathbf{2}$ & $0.992(1)$ & $1.786(2)$ & $2.683(2)$ & $148.3(1)$ \\
$\mathbf{3}$ & $0.840(4)$ & $1.962(4)$ & $2.683(6)$ & $143.6(3)$ \\
\hline
\end{tabular}




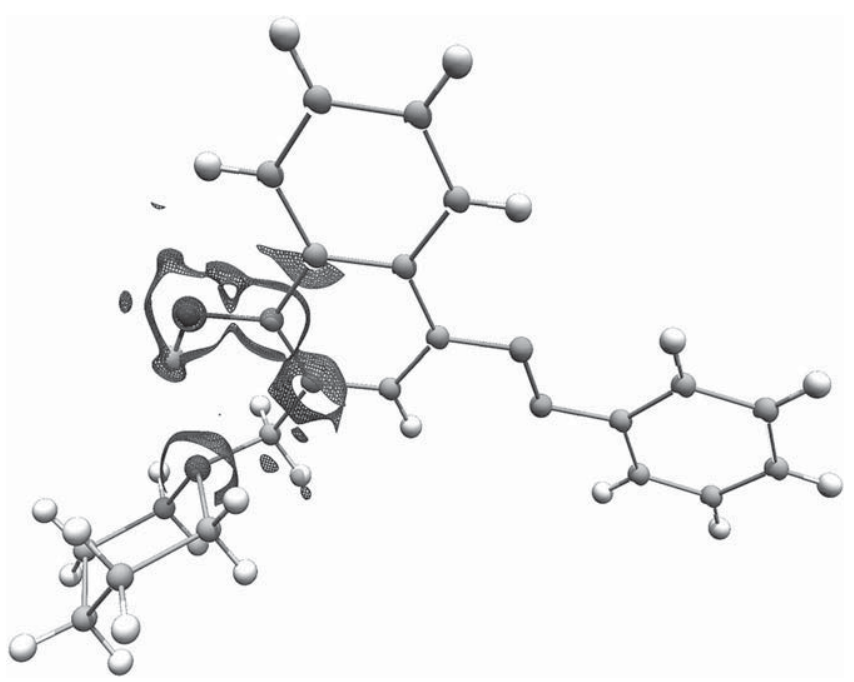

Fig. 2. Fourier map of 2.

compounds, shown in Figs. 3, 5, 7 and Fig. S3, does not indicate intermolecular interactions, which could influence their use as reference compounds for the pure tautomers.

\subsection{Bond lengths analysis}

The averaged lengths of the most sensitive bonds (according to the numbering from Scheme 2) included in the main tautomeric skeleton are collected in Table 2 and visualized in Fig. 8. These data correspond to the statistically evaluated by Kelemen et al. [27] intervals for the pure enol $(1.37 \AA<\mathrm{C} 1-\mathrm{N} 1<1.49 \AA$ and $1.20 \AA<\mathrm{N} 1=\mathrm{N} 2<1.28 \AA)$ and pure keto form $(1.35 \AA<\mathrm{C} 1-\mathrm{N} 1<$ $1.47 \AA, 1.30 \AA<\mathrm{N} 1-\mathrm{N} 2<1.43 \AA$ and $1.26 \AA<\mathrm{N} 2=\mathrm{C} 2<1.33 \AA)$. According to Harada et al. [28] in nondisordered azobenzenes the
$\mathrm{N}-\mathrm{N}$ double bond has a length of $1.26-1.27 \AA$, which is also in an excellent agreement with the enol $\mathrm{N} \equiv \mathrm{N}$ bond length presented in Table 2. In addition the evaluation of the bond lengths for 2-4 and 10Me show that there are no significant deviations caused by the attachment of spacer at C4 (in the case of $\mathbf{2}$ and $\mathbf{3}$ ) or Me group at the $\mathrm{O} 1 \mathrm{atom}$ (at 10Me).

The results shown in Fig. 8 can yield some important remarks. It is clearly seen that the $\mathrm{C} 2-\mathrm{C} 3-\mathrm{C} 4-\mathrm{C} 5-\mathrm{O} 1$ fragment is strongly dependent by the kind of the tautomer. In the enol tautomer a conjugation leading to almost the same bond lengths is evident, while in the keto structure a well-defined alternation is available. In addition the bond $\mathrm{C} 1-\mathrm{N} 1$ is not suitable for evaluation purposes since the enol and keto form have the same values in the frame of the statistical error. The data from Table 2 show that the differences in the bonds $\mathrm{C} 2-\mathrm{C} 11$ and $\mathrm{C} 5-\mathrm{C} 6$ are smaller comparing to $\mathrm{C} 2-\mathrm{C} 3$ and $\mathrm{C} 4-\mathrm{C} 5$, which is case to their direct connection to the aromatic ring $\mathrm{C} 6-\mathrm{C} 11$, which is practically not affected by the kind of the tautomeric structure. Although the differences between the tautomeric structures are most pronounced in N1-N2, N2-C2 and C5-O1 bonds, the total statistical analysis is performed for the whole tautomeric skeleton (bonds from N1 to O1, namely N1-N2, $\mathrm{N} 2-\mathrm{C} 2, \mathrm{C} 2-\mathrm{C} 3, \mathrm{C} 3-\mathrm{C} 4, \mathrm{C} 4-\mathrm{C} 5, \mathrm{C} 5-\mathrm{O} 1$, Scheme 2).

The overall pictures for the total deviations in predicting the bonds of the fragment N1-O1 is presented in Table 3. Detailed information about each bond description can be found in Figs. S4-S32.

As seen the bond lengths are predicted reasonably well. The exceptions are observed when very restricted basis sets are used (all methods except HF with CEP, 6-31G and D95 basis sets). The performance of HF calculations is worse as whole except with the above mentioned basis sets. It is quite common that basis set incompleteness introduces errors opposite to that from failure to account for electron correlation, leading in cases to fortuitously good HF results with small to medium basis sets, whereas with the better basis larger errors are produced [1]. In the case of LC-BLYP the substantial HF contribution (this contribution originates from

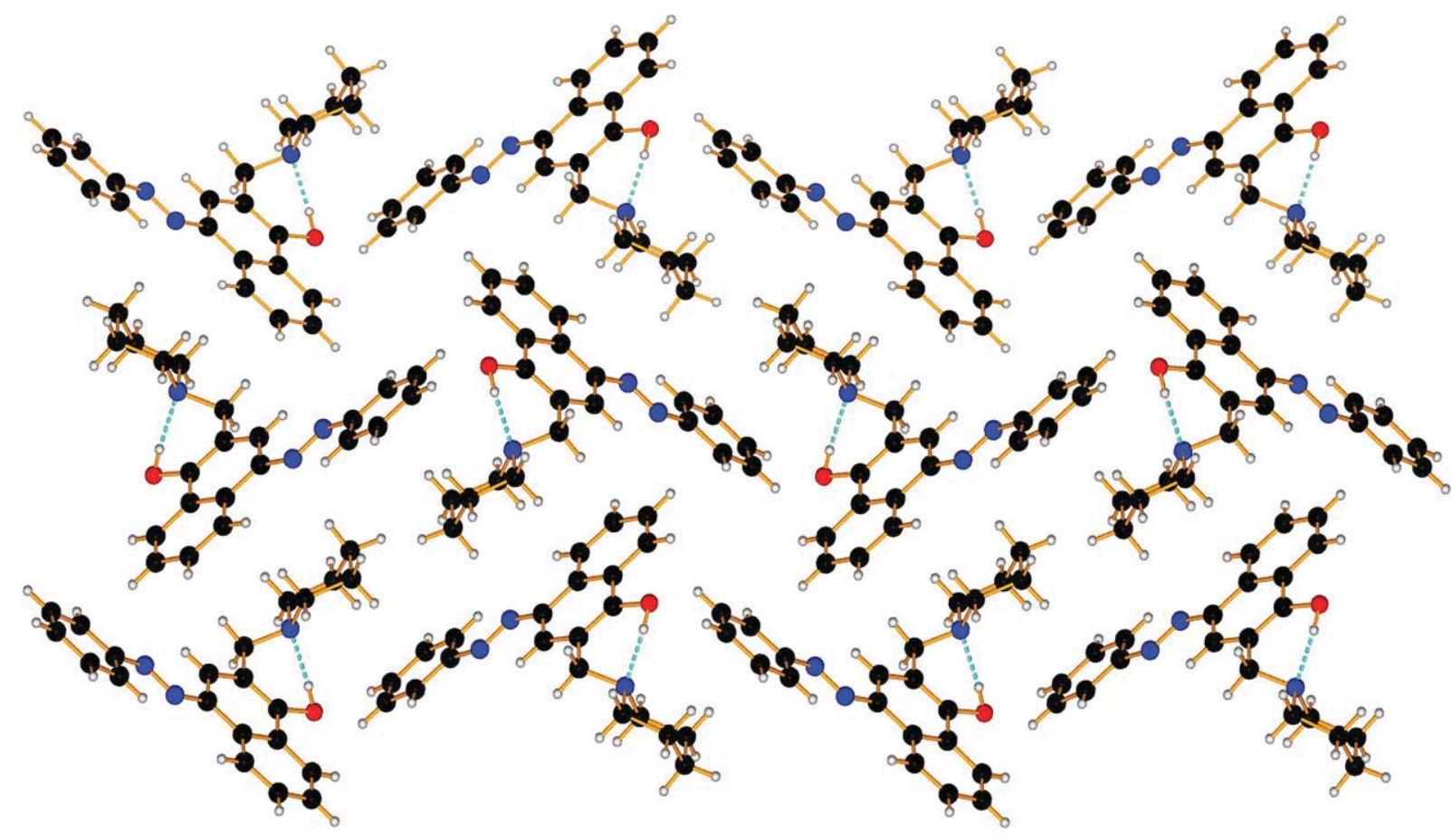

Fig. 3. View along the $a$ axis of the molecular structure of $\mathbf{2}$ with hydrogen bonds indicated as dashed blue lines (For interpretation of the references to color in this figure legend, the reader is referred to the web version of this article.). 


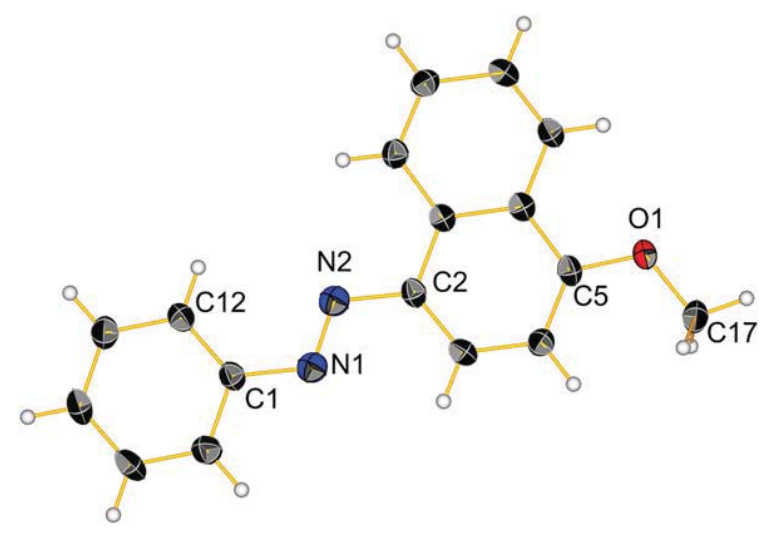

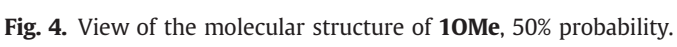

the HF exchange potential used in the long-range part of the Coulomb operator) leads to the same tendencies (bonds are predicted shorter or longer as in HF), but with lower deviations. The DFT prediction is in most of the cases in the frame of the statistical error of determination of the experimental bond lengths in the case of the enol form. In the case of the keto form the bond length description is worse. One can expect that the introduction of the methyl group at N1 in $\mathbf{1 N M e}$ is the possible reason. However there are no systematic deviations in the N1-N2 and N2-C2 keto bonds description (Figs. S10 and S11).

The conclusion, which can be made from Table 3, is that the pure, hybrid and double hybrid methods give larger extent of flexibility, providing very good description at a number of medium to large basis sets. From statistical point of view the description of B3LYP and B3PW91 (with 6-31G** to 6-311++ $\mathrm{G}^{* *}$, cc-pVDZ - ccpVQZ, TZVP and QZVP), B2PLYP and MPW2PLYP (with 6-31G** $6-311++\mathrm{G}^{* *}, \mathrm{cc}-\mathrm{pVTZ}$ and TZVP) is indiscernible. The results for the double hybrid functionals are slightly better and the best description is achieved at B2PLYP/cc-pVTZ and B2PLYP/TZVP.

\subsection{Planarity analysis}

Additional feature that can help us to evaluate the reliability of theoretical calculations is prediction of the planarity of the tautomers. In the case of $\mathbf{1 N M e}$ the presence of large methyl group at $\mathrm{N} 1$ makes impossible to draw conclusions about the planarity of the individual keto tautomer 1K. However, in the case of 2, 3 and

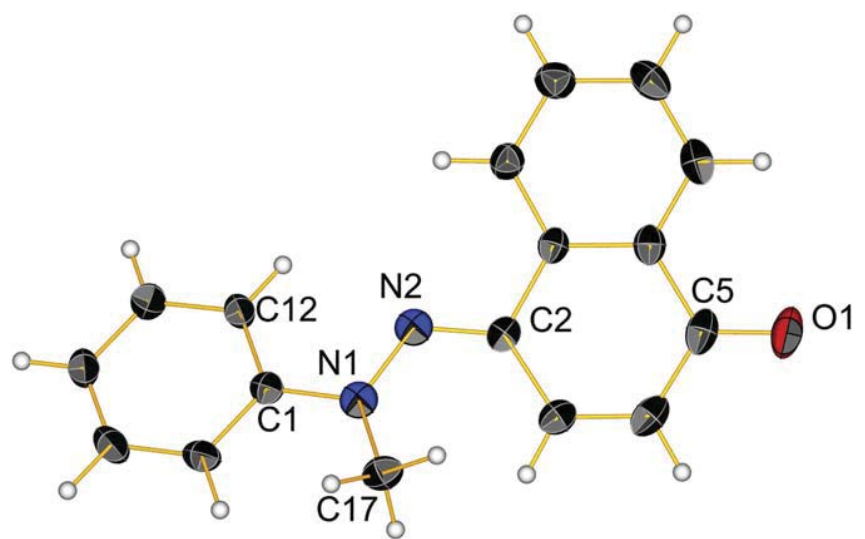

Fig. 6. View of the molecular structure of $\mathbf{1 N M e}, 50 \%$ probability.

10Me there is no steric hindrance in the $\mathrm{C} 1-\mathrm{N} 1-\mathrm{N} 2-\mathrm{C} 2$ fragment neither large packing density to forced planarization. As a consequence we can assume that they provide reliable information about the $\mathrm{C} 12-\mathrm{C} 1-\mathrm{N} 1-\mathrm{N} 2$ dihedral angle. The corresponding values are shown in Table 4 and Fig. 9. It is obvious that in this case only qualitative evaluation can be made. HF predicted structures are nonplanar except using small basis sets like CEP31, 6-31 and D95, while at MP2 level an overestimating tendency is observed. B3LYP and B3PW91 optimized structures of tautomers are planar independent on the basis set used. OLYP and LC-BLYP calculated dihedral angles correspond to experimental values when Pople style spbasis sets combined with diffusion (s- and $\mathrm{p}-$ ) functions are used (except OLYP/6-31+G* result); with Dunning's correlation consistent and Ahlrichs TZVP basis sets the values are overestimated. B2PLYP and mPW2PLYP structures are nonplanar when Pople style sp- basis sets with diffusion functions and Ahlrichs TZVP and QZVP basis sets are used.

\subsection{The tautomeric equilibrium in solution}

When a tautomeric compound is investigated the main question one can ask is about the relative stability of the individual tautomers. In quantitative terms the relative stability is defined by the tautomeric constant and the corresponding $\Delta G$ value at room temperature. In the case of $\mathbf{1}$ the Gibbs free energy has been determined in three non-polar solvents: cyclohexane (1.42 kcal $\left.\mathrm{mol}^{-1}\right)$ [5], methylcyclohexane/toluene $\left(1.26 \mathrm{kcal} \mathrm{mol}^{-1}\right)$ [5] and in

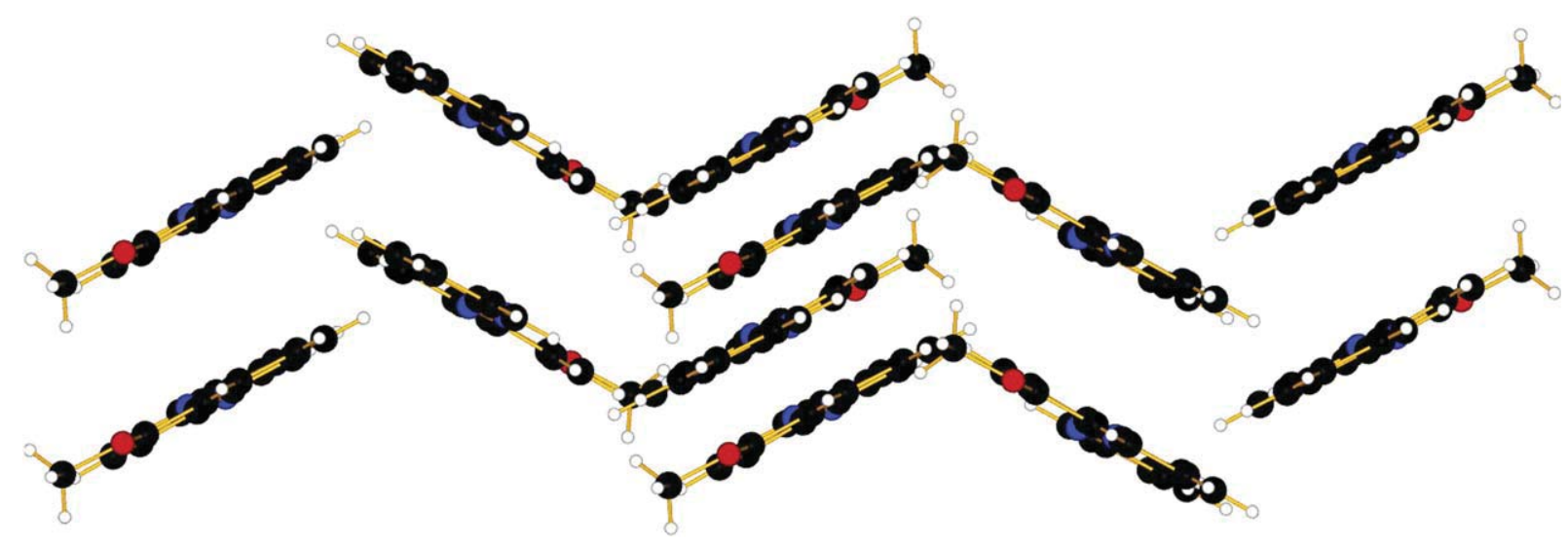

Fig. 5. View of the molecular packing of 10Me. 


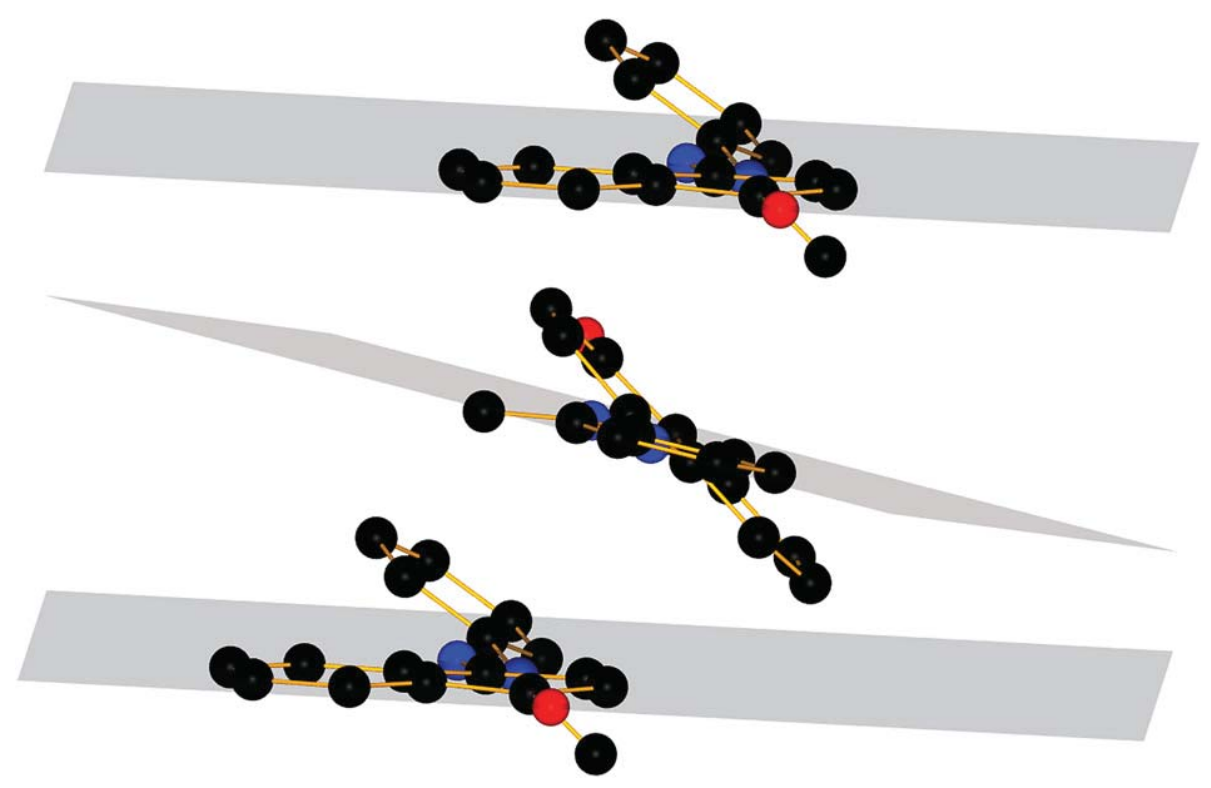

Fig. 7. Packing of $\mathbf{1 N M e .}$

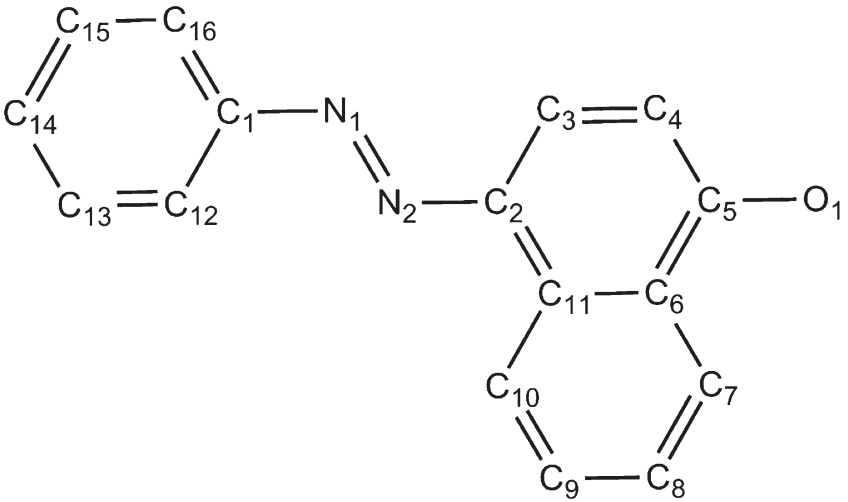

Scheme 2. Numbering in the backbone structure of the tautomeric forms.

Table 2

Averaged values for the decisive bond lengths of the enol (taken from 2-4 and 10Me) and the keto form (taken from 1NMe). For the numbering of the atoms see Scheme 2.

\begin{tabular}{|c|c|c|c|c|c|c|}
\hline \multirow[t]{2}{*}{ Bond } & \multicolumn{5}{|c|}{ E-form $[\AA ̊]$} & \multirow[t]{2}{*}{ K-form $[\AA$} \\
\hline & 2 & 3 & 4 & 10Me & Averaged & \\
\hline $\mathrm{C} 1-\mathrm{N} 1$ & $1.428(3)$ & $1.427(8)$ & $1.420(3)$ & $1.429(4)$ & $1.426(9)$ & $1.414(4)$ \\
\hline $\mathrm{N} 1-\mathrm{N} 2$ & $1.262(3)$ & $1.259(7)$ & $1.263(3)$ & $1.266(3)$ & $1.263(8)$ & $1.347(4)$ \\
\hline $\mathrm{N} 2-\mathrm{C} 2$ & $1.410(3)$ & $1.422(7)$ & $1.424(3)$ & $1.429(4)$ & 1.421(9) & $1.316(4)$ \\
\hline $\mathrm{C} 2-\mathrm{C} 3$ & $1.385(3)$ & $1.375(8)$ & $1.371(4)$ & $1.372(4)$ & $1.37(1)$ & $1.445(4)$ \\
\hline C3-C4 & $1.386(4)$ & $1.379(8)$ & $1.395(3)$ & $1.401(4)$ & $1.39(1)$ & $1.348(5)$ \\
\hline $\mathrm{C} 4-\mathrm{C} 5$ & $1.378(4)$ & $1.390(8)$ & $1.376(4)$ & $1.376(4)$ & $1.38(1)$ & $1.446(5)$ \\
\hline C5-O1 & $1.360(3)$ & $1.348(7)$ & $1.356(3)$ & $1.370(3)$ & $1.359(8)$ & $1.242(4)$ \\
\hline $\mathrm{C} 2-\mathrm{C} 11$ & $1.433(3)$ & $1.435(8)$ & $1.438(8)$ & $1.434(4)$ & $1.43(1)$ & $1.481(5)$ \\
\hline C5-C6 & $1.431(3)$ & $1.442(7)$ & $1.431(4)$ & $1.420(4)$ & $1.431(9)$ & $1.479(4)$ \\
\hline C6-C11 & $1.422(4)$ & $1.413(8)$ & $1.425(3)$ & $1.429(4)$ & $1.42(1)$ & $1.404(5)$ \\
\hline C6-C7 & $1.414(4)$ & $1.414(8)$ & $1.408(4)$ & $1.413(4)$ & $1.41(1)$ & $1.400(5)$ \\
\hline $\mathrm{C} 7-\mathrm{C} 8$ & $1.369(3)$ & $1.379(8)$ & $1.354(4)$ & $1.368(4)$ & $1.36(1)$ & $1.367(5)$ \\
\hline $\mathrm{C} 8-\mathrm{C} 9$ & $1.401(4)$ & $1.406(9)$ & $1.399(3)$ & $1.409(4)$ & $1.40(1)$ & $1.389(6)$ \\
\hline $\mathrm{C} 9-\mathrm{C} 10$ & $1.355(4)$ & $1.374(8)$ & $1.370(4)$ & $1.371(4)$ & $1.36(1)$ & $1.373(5)$ \\
\hline $\mathrm{C} 10-\mathrm{C} 11$ & 1.421(3) & $1.416(8)$ & $1.401(4)$ & $1.413(4)$ & 1.41(1) & $1.401(4)$ \\
\hline
\end{tabular}

i-octane $\left(1.38 \mathrm{kcal} \mathrm{mol}^{-1}\right)$ at $298 \mathrm{~K}$. These values mean that the enol tautomer is strongly dominating (more than 90\%). Taking into account that in the used solvents there are no possibilities for specific interactions, the evaluated free energies are suitable to test the quantum chemical prediction of the relative stability of the tautomers. In Fig. 10 and in Table 5 the experimental values are compared with the $\Delta G$ values obtained from the frequency calculations. In the Figs. S32 and S33 the same comparisons are made with the differences in total energies $\left(\Delta E_{\mathrm{T}}\right)$ and in enthalpies $\left(\Delta E_{\mathrm{T}}+\mathrm{ZPE}\right)$ values.

The quantum chemical data presented in the figures are for gas phase. Taking into account that: the solvents used for comparison are low polar; the keto form is slightly more polar; the usual error of determination of the molar fraction of the enol tautomer is

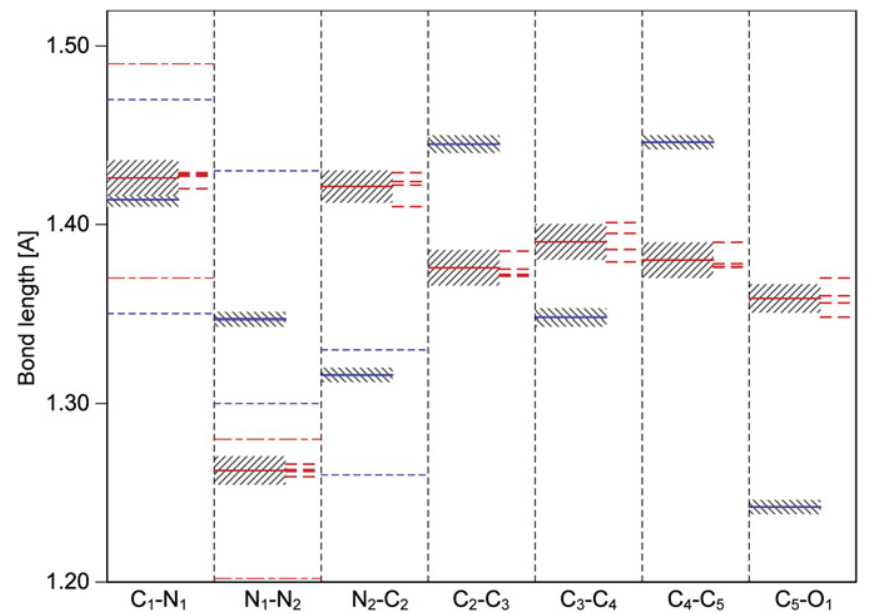

Fig. 8. The averaged lengths of the bonds (with standard deviations as shadowed fields) from the main tautomeric skeleton (see Scheme 2 for the numbering) for the enol (red) and the keto (blue) form. In the case of the enol form the individual values for 2-4 and 10Me are given on the right side. For bonds $\mathrm{C} 1-\mathrm{N} 1, \mathrm{~N} 1-\mathrm{N} 2$ and N2-C2 with dashed lines are marked the lengths intervals of the pure enol and keto form determined by Kelemen [27]. (For interpretation of the references to color in this figure legend, the reader is referred to the web version of this article). 
Table 3

Sums of the absolute values for the relative deviations ${ }^{\mathrm{a}}$ (in percents) in respect to the real values taken from Table 2 for the whole N1-01 fragment of the individual tautomers. The shadowed cells mark deviation in the frame of the statistical error of experimental determination of the bond lengths.

\begin{tabular}{|c|c|c|c|c|c|c|c|c|c|c|c|c|}
\hline \multirow[t]{2}{*}{ Basis set } & \multicolumn{3}{|l|}{$\mathrm{HF}$} & \multicolumn{3}{|l|}{ MP2 } & \multicolumn{3}{|l|}{ OLYP } & \multicolumn{3}{|l|}{ B3LYP } \\
\hline & $\mathbf{E}$ & $\mathbf{K}$ & Total & $\mathbf{E}$ & $\mathbf{K}$ & Total & $\mathbf{E}$ & $\mathbf{K}$ & Total & $\mathbf{E}$ & $\mathbf{K}$ & Total \\
\hline CEP31G & 7.38 & 8.11 & 15.49 & 26.36 & 23.56 & 49.92 & 14.57 & 12.09 & 26.66 & 15.49 & 13.16 & 28.65 \\
\hline $6-31 G$ & 6.51 & 9.03 & 15.54 & 14.21 & 11.49 & 25.71 & 9.78 & 7.87 & 17.65 & 6.71 & 5.13 & 11.84 \\
\hline $6-31 G^{* *}$ & 7.67 & 13.97 & 21.64 & 5.29 & 4.51 & 9.80 & 6.10 & 6.12 & 12.22 & 3.37 & 5.34 & 8.71 \\
\hline $6-31+G^{*}$ & 7.57 & 13.50 & 21.07 & 6.10 & 4.87 & 10.97 & 6.34 & 6.33 & 12.67 & 3.84 & 5.15 & 8.99 \\
\hline $6-31+\mathrm{G}^{* *}$ & 7.64 & 13.62 & 21.26 & 5.98 & 4.46 & 10.44 & 6.30 & 6.28 & 12.59 & 3.38 & 5.33 & 8.70 \\
\hline $6-31++\mathrm{G}^{* *}$ & 7.63 & 13.59 & 21.22 & 5.94 & 4.68 & 10.62 & 6.30 & 6.29 & 12.59 & 3.76 & 5.12 & 8.87 \\
\hline $6-311++G^{* *}$ & 8.34 & 14.55 & 22.89 & 5.25 & 5.85 & 11.10 & 5.21 & 5.94 & 11.15 & 3.33 & 5.71 & 9.04 \\
\hline D95 & 5.80 & 8.31 & 14.11 & 20.27 & 16.71 & 36.98 & 12.70 & 10.05 & 22.76 & 9.71 & 7.46 & 17.17 \\
\hline D95** & 6.96 & 13.47 & 20.43 & 7.44 & 5.99 & 13.43 & 7.66 & 7.01 & 14.66 & 5.16 & 5.67 & 10.83 \\
\hline $\mathrm{D} 95++^{* *}$ & 7.04 & 13.47 & 20.51 & 7.44 & 5.93 & 13.37 & 7.24 & 6.90 & 14.13 & 4.81 & 5.51 & 10.32 \\
\hline cc-pVDZ & 7.55 & 14.03 & 21.58 & 6.60 & 7.70 & 14.31 & 5.96 & 6.76 & 12.72 & 3.65 & 5.95 & 9.60 \\
\hline cc-pVTZ & 8.95 & 15.14 & 24.09 & 3.64 & 5.93 & 9.57 & 4.23 & 5.65 & 9.88 & 2.86 & 6.11 & 8.96 \\
\hline cc-pVQZ & 9.26 & 15.45 & 24.71 & & & & 4.16 & 5.72 & 9.89 & 2.95 & 6.25 & 9.19 \\
\hline SVP & & & & & & & 6.15 & 7.63 & 13.78 & 4.92 & 7.29 & 12.21 \\
\hline TZVP & & & & & & & 4.55 & 5.61 & 10.16 & 3.02 & 5.89 & 8.91 \\
\hline \multirow[t]{3}{*}{ QZVP } & & & & & & & 9.00 & 7.01 & 16.01 & 5.84 & 4.11 & 9.96 \\
\hline & \multicolumn{3}{|c|}{ В3РW91 } & \multicolumn{3}{|c|}{ LC-BLYP } & \multicolumn{3}{|c|}{ B2PLYP } & \multicolumn{3}{|c|}{ mPW2PLYP } \\
\hline & $\mathbf{E}$ & $\mathbf{K}$ & Total & $\mathbf{E}$ & $\mathbf{K}$ & Total & $\mathbf{E}$ & $\mathbf{K}$ & Total & $\mathbf{E}$ & $\mathbf{K}$ & Total \\
\hline CEP31G & 13.35 & 11.17 & 24.52 & 9.28 & 9.12 & 18.39 & 18.46 & 16.07 & 34.53 & 16.90 & 14.63 & 31.54 \\
\hline $6-31 G$ & 5.93 & 4.78 & 10.72 & 5.13 & 6.67 & 11.79 & 8.06 & 6.34 & 14.40 & 6.76 & 5.37 & 12.13 \\
\hline $6-31 G^{* *}$ & 3.41 & 5.64 & 9.04 & 6.20 & 10.99 & 17.18 & 3.70 & 4.60 & 8.31 & 2.65 & 4.96 & 7.61 \\
\hline $6-31+\mathrm{G}^{*}$ & 3.46 & 5.48 & 8.94 & 6.02 & 10.50 & 16.52 & 4.24 & 4.57 & 8.81 & 3.17 & 4.69 & 7.86 \\
\hline $6-31+\mathrm{G}^{* *}$ & 3.44 & 5.46 & 8.89 & 6.07 & 10.50 & 16.58 & 4.15 & 4.51 & 8.66 & 3.08 & 4.67 & 7.75 \\
\hline $6-31++\mathrm{G}^{* *}$ & 3.44 & 5.45 & 8.89 & 6.08 & 10.50 & 16.59 & 4.14 & 4.51 & 8.65 & 3.09 & 4.67 & 7.75 \\
\hline $6-311++\mathrm{G}^{* *}$ & 3.35 & 5.95 & 9.31 & 7.26 & 11.88 & 19.13 & 3.14 & 5.04 & 8.18 & 2.92 & 5.62 & 8.54 \\
\hline D95 & 8.23 & 6.79 & 15.02 & 3.72 & 5.84 & 9.56 & 12.68 & 10.29 & 22.97 & 11.00 & 8.73 & 19.73 \\
\hline D95** & 4.09 & 5.69 & 9.78 & 5.07 & 10.26 & 15.34 & 5.56 & 5.36 & 10.91 & 4.46 & 5.14 & 9.60 \\
\hline D95 $++^{* *}$ & 3.75 & 5.62 & 9.37 & 5.19 & 10.33 & 15.53 & 5.27 & 5.21 & 10.48 & 4.16 & 5.00 & 9.16 \\
\hline cc-pVDZ & 3.93 & 6.11 & 10.04 & 6.25 & 11.12 & 17.37 & 4.16 & 6.16 & 10.32 & 3.21 & 5.94 & 9.15 \\
\hline cc-pVTZ & 3.36 & 6.67 & 10.04 & 7.97 & 12.25 & 20.21 & 2.41 & 4.95 & 7.36 & 2.71 & 5.93 & 8.64 \\
\hline cc-pVQZ & 3.56 & 6.93 & 10.49 & 8.13 & 12.43 & 20.56 & & & & & & \\
\hline SVP & 5.46 & 7.47 & 12.93 & 7.13 & 12.23 & 19.36 & 4.44 & 6.68 & 11.12 & 4.61 & 7.18 & 11.80 \\
\hline TZVP & 3.18 & 6.38 & 9.56 & 7.73 & 12.25 & 19.98 & 2.62 & 4.73 & 7.36 & 2.81 & 5.66 & 8.47 \\
\hline QZVP & 5.03 & 3.74 & 8.77 & 6.00 & 7.08 & 13.08 & 7.55 & 5.45 & 13.01 & 6.02 & 4.01 & 10.03 \\
\hline
\end{tabular}

a Defined as $\sum\left|\left(r_{\text {predicted }}-r_{\text {real }}\right) / r_{\text {real }}\right| \cdot 100$, where $r_{\text {predicted }}$ is the bond length obtained as result of the optimization at the corresponding method/basis set and $r_{\text {real }}$ is the value obtained as result of X-ray structure determination (Table 2 ).

Table 4

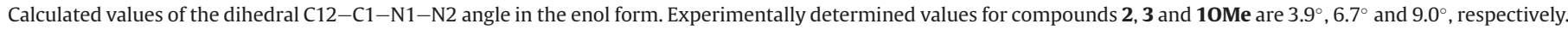

\begin{tabular}{|c|c|c|c|c|c|c|c|c|c|c|c|c|c|c|c|c|}
\hline & CEP-31G & $6-31 G$ & $6-31 G^{* *}$ & $6-31+G^{*}$ & $6-31+\mathrm{G}^{* *}$ & $6-31++G^{* *}$ & $6-311++G^{* *}$ & D95 & D95** & D95 $++{ }^{* *}$ & cc-pVDZ & cc-pVTZ & cc-pVQZ & SVP & TZVP & QZVP \\
\hline $\mathrm{HF}$ & 0.1 & 0.0 & 6.4 & 7.8 & 8.9 & 8.6 & 10.0 & 0.0 & 5.0 & 0.0 & 8.5 & 9.8 & 9.3 & & & \\
\hline MP2 & 8.5 & 3.4 & 12.0 & 19.1 & 19.5 & 20.0 & 19.9 & 8.8 & 9.9 & 14.5 & 12.7 & 11.7 & & & & \\
\hline OLYP & 0.0 & 0.0 & 0.0 & 0.0 & 9.0 & 8.9 & 11.2 & 0.0 & 0.1 & 0.0 & 12.2 & 13.1 & 13.0 & 9.9 & 11.4 & 0.0 \\
\hline B3LYP & 0.0 & 0.0 & 0.1 & 0.0 & 0.0 & 0.0 & 0.1 & 0.0 & 0.0 & 0.0 & 0.0 & 0.1 & 0.0 & 0.0 & 0.0 & 0.0 \\
\hline B3PW91 & 0.0 & 0.0 & 0.0 & 0.0 & 0.0 & 0.0 & 0.1 & 0.0 & 0.0 & 0.0 & 0.0 & 0.0 & 0.1 & 0.0 & 0.0 & 0.1 \\
\hline LC-BLYP & 0.0 & 0.0 & 0.0 & 8.0 & 9.1 & 9.8 & 11.1 & 0.0 & 0.0 & 0.0 & 9.8 & 13.1 & 12.3 & 0.0 & 11.6 & 0.0 \\
\hline B2PLYP & 0.0 & 0.0 & 0.0 & 10.9 & 11.3 & 11.2 & 11.7 & 0.0 & 0.0 & 0.0 & 0.0 & 0.0 & & 0.1 & 14.2 & 13.2 \\
\hline mPW2PLYP & 0.0 & 0.1 & 0.0 & 10.4 & 10.8 & 10.7 & 11.3 & 0.0 & 0.0 & 0.0 & 0.0 & 0.0 & & 0.1 & 13.6 & 12.5 \\
\hline
\end{tabular}

within $5 \%$, the theoretical data in the area $1-1.5 \mathrm{kcal} \mathrm{mol}^{-1}$ or slightly higher ${ }^{3}$ can be considered as a correct description of the tautomeric equilibrium. The data clearly show that HF method reasonably describes the real situation in solution at using of most of the basis sets. Overestimation is observed at $\mathrm{HF} / 6-$ $31+\mathrm{G}^{* *}$ and $\mathrm{HF} / 6-31++\mathrm{G}^{* *}$ levels and underestimation can be seen at $\mathrm{HF} / 6-31+\mathrm{G}^{*}$ and with Dunning's correlation consistent basis

\footnotetext{
${ }^{3}$ The inclusion of the solvent effect in the calculations should slightly stabilize the keto tautomer as more polar, which could lead to slight decrease of the $\Delta G$ value in general in the absence of specific solute-solvent interactions.
}

sets. The MP2 calculations erroneously predict strong predominance of the enol tautomer except at very constrained basis sets (6-31G and D95) where the keto form is considered as more stable.

The tested pure (OLYP) and hybrid functionals (B3LYP and B3PW91) fail in the prediction of the position of the equilibrium independent on the basis set. The situation is slightly better at the long range corrected functional (LC-BLYP), which give predominance of the enol tautomer at $6-31+\mathrm{G}^{* *}$ and $\mathrm{D} 95++^{* *}$. The double hybrid functionals give very good description with $\mathrm{D} 95+{ }^{* *}$ basis set. In addition B2PLYP predict more stable enol tautomer with ccpVDZ and cc-pVTZ, while both functionals (LC-BLYP and B2PLYP) give almost equal stability with $6-31 G^{* *}$ and $6-311++G^{* *}$. 


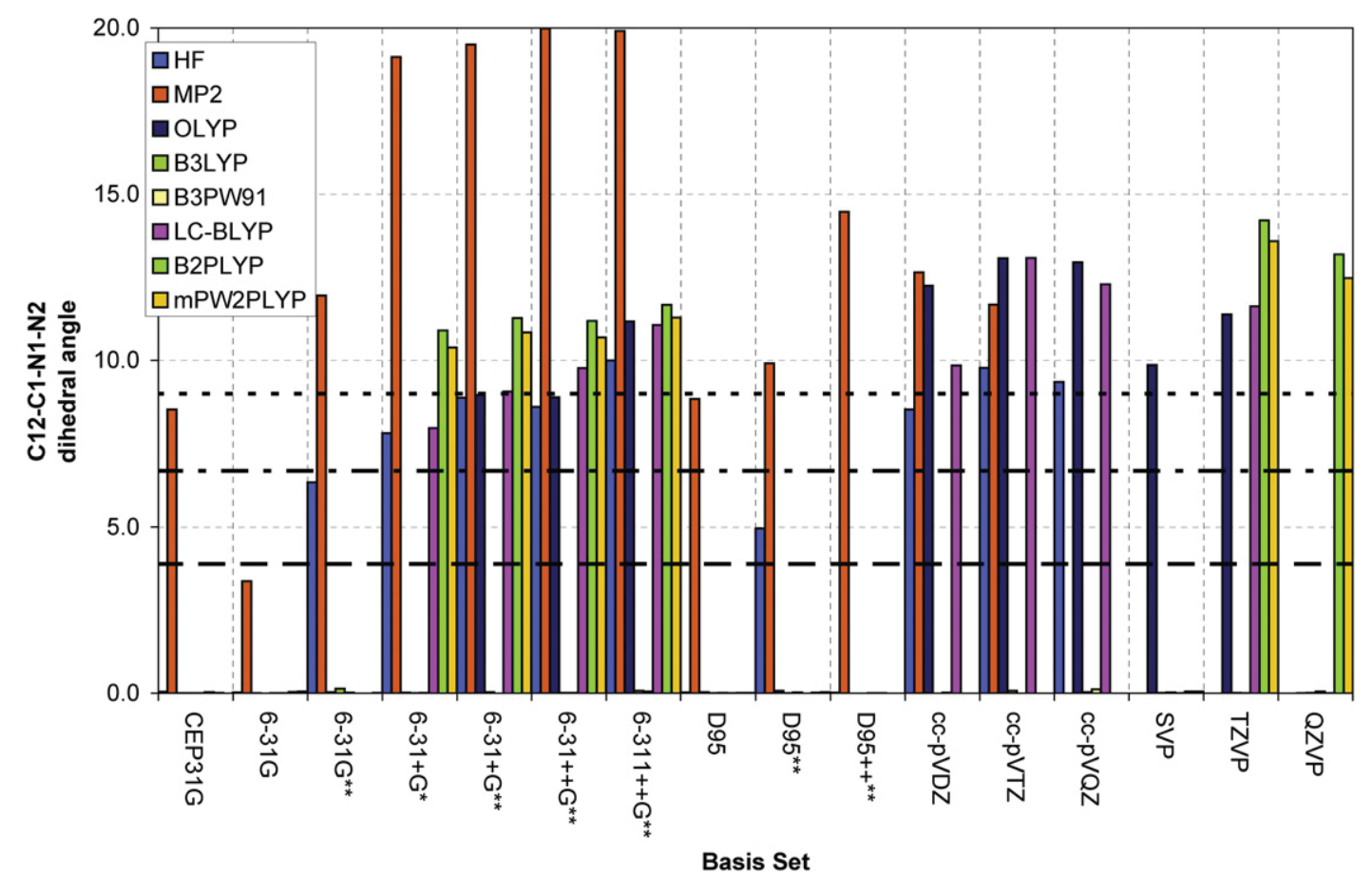

Fig. 9. Estimated and experimentally determined $(2---, 3---, \mathbf{1 0 M e}---)$ values of the dihedral $\mathrm{C} 12-\mathrm{C} 1-\mathrm{N} 1-\mathrm{N} 2$ angle in the enol tautomer.

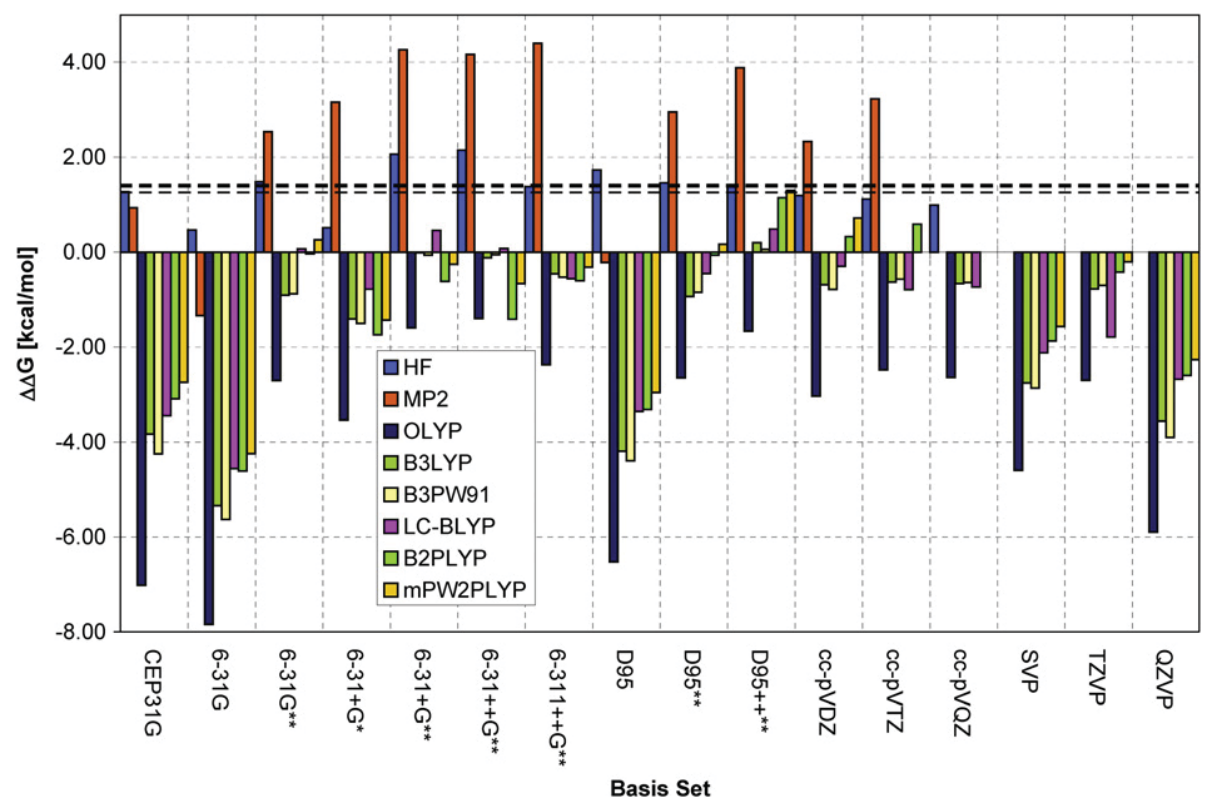

Fig. 10. Estimated and experimentally determined (with dashes) $\Delta G$ values at room temperature. Positive value corresponds to more stable enol form and vice versa.

Table 5

Calculated $\Delta G$ values (in $\mathrm{kcal} / \mathrm{mol}$ units) at room temperature. Positive value corresponds to more stable enol form and vice versa. Experimentally determined values in cyclohexane, methylcyclohexane/toluene and i-octane solutions are $1.42,1.26$ and $1.38 \mathrm{kcal} \mathrm{mol}^{-1}$, respectively.

\begin{tabular}{|c|c|c|c|c|c|c|c|c|c|c|c|c|c|c|c|c|}
\hline & CEP-31G & $6-31 G$ & $6-31 G^{* *}$ & $6-31+\mathrm{G}^{*}$ & $6-31+\mathrm{G}^{* *}$ & $6-31++\mathrm{G}^{* *}$ & $6-311++G^{* *}$ & D95 & D95** & D95++ ${ }^{* *}$ & cc-pVDZ & cc-pVTZ & cc-pVQZ & SVP & TZVP & QZVP \\
\hline $\mathrm{HF}$ & 1.27 & 0.47 & 1.48 & 0.51 & 2.06 & 2.15 & 1.38 & 1.73 & 1.46 & 1.37 & 1.19 & 1.12 & 0.99 & & & \\
\hline MP2 & 0.93 & -1.34 & 2.53 & 3.16 & 4.26 & 4.16 & 4.40 & -0.22 & 2.95 & 3.88 & 2.33 & 3.22 & & & & \\
\hline OLYP & -7.01 & -7.83 & -2.70 & -3.53 & -1.60 & -1.40 & -2.37 & -6.52 & -2.65 & -1.66 & -3.03 & -2.48 & -2.64 & -4.59 & -2.70 & -5.89 \\
\hline B3LYP & -3.83 & -5.34 & -0.90 & -1.41 & -0.01 & -0.12 & -0.46 & -4.19 & -0.93 & 0.20 & -0.68 & -0.63 & -0.66 & -2.75 & -0.78 & -3.56 \\
\hline B3PW91 & -4.24 & -5.62 & -0.88 & -1.50 & -0.06 & -0.05 & -0.53 & -4.39 & -0.84 & 0.06 & -0.78 & -0.57 & -0.64 & -2.86 & -0.70 & -3.90 \\
\hline LC-BLYP & -3.45 & -4.55 & 0.07 & -0.78 & 0.46 & 0.08 & -0.56 & -3.35 & -0.45 & 0.48 & -0.29 & -0.79 & -0.73 & -2.12 & -1.78 & -2.68 \\
\hline B2PLYP & -3.09 & -4.61 & -0.04 & -1.74 & -0.61 & -1.41 & -0.60 & -3.31 & -0.06 & 1.15 & 0.33 & 0.59 & & -1.87 & -0.42 & -2.60 \\
\hline mPW2PLYP & -2.74 & -4.24 & 0.26 & -1.43 & -0.25 & -0.66 & -0.31 & -2.96 & 0.17 & 1.30 & 0.72 & & & -1.57 & -0.20 & -2.27 \\
\hline
\end{tabular}




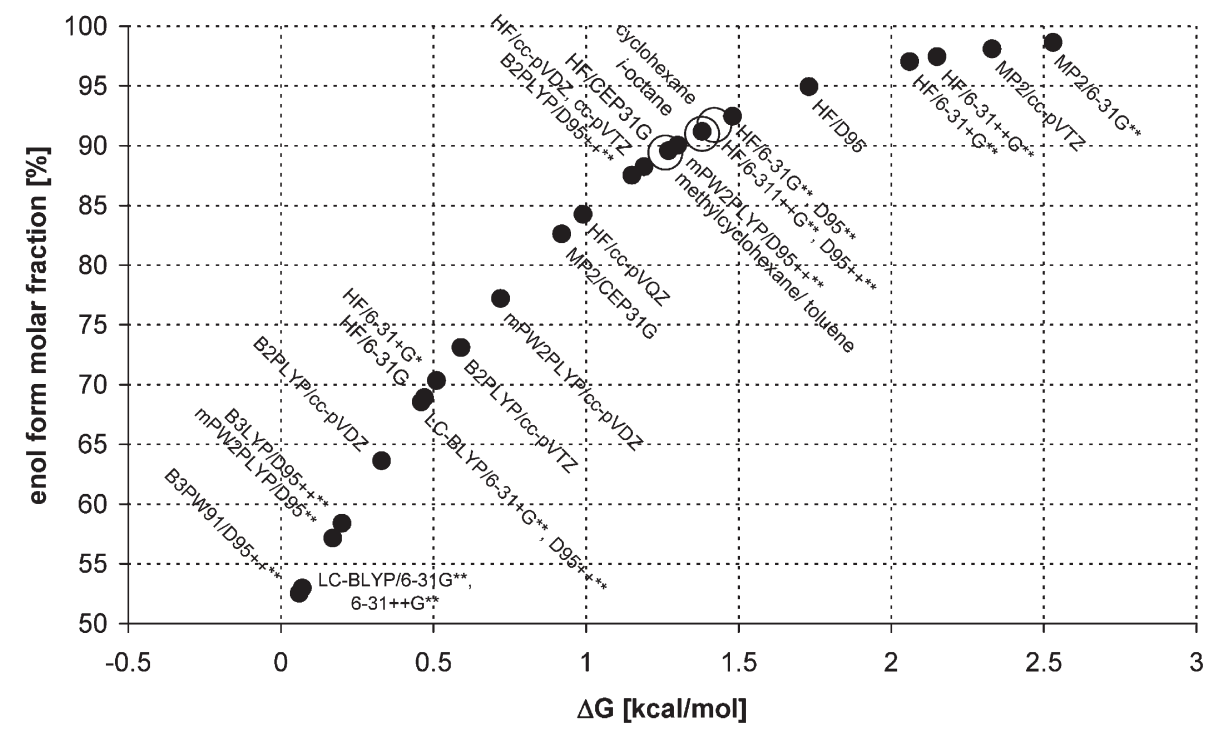

Fig. 11. Molar fractions of the enol form as a function of the experimentally determined and the best of the theoretically predicted free energies.

The improvement afforded by polarization functions on DFT results is notable for basis sets not including polarization function in definition (CEP-31G, 6-31G, D95). The adding of polarization (d,p) functions to 6-31G and D95 basis sets brings the calculated relative energies closer to experimental findings. The effect of diffuse functions is smaller when we compare $6-31 G^{* *}$ to $6-31+G^{* *}$ and $6-31++\mathrm{G}^{* *}$ results and significant in the case of D95 basis set.

Fig. 11 shows some of the results for $\Delta G$ against molar fraction of the enol form and illustrates in more practical manner the performances of the different levels of calculations and basis sets. As can be seen in the target zone between $\Delta G$ values of 1 to $1.5 \mathrm{kcal} \mathrm{mol}^{-1}$ (85-95\% enol) are placed some HF results, B2PLYP and mPW2PLYP calculated with D95 $++^{* *}$ basis set. Taking into account the data one can conclude that HF with $6-31 G^{* *}, 6-$ $311++\mathrm{G}^{* *}$ and Dunning/Huzinaga full double zeta basis sets with addition of polarization and diffuse functions are suitable for correct description of the tautomeric equilibrium. From the DFT functionals only B2PLYP and MPW2PLYP at D95 $++^{* *}$ provide very accurate prediction.

\section{Conclusion}

The comparison of the crystallographic data with the optimized theoretical structures, on one side, and the experimentally obtained $\Delta G$ values in solution with the predicted ones, on the other side, give confusing results about the reliability of the quantum-chemical prediction of the tautomerism of $\mathbf{1}$.

Although the HF calculations give worst description of the bond lengths (but with the deviation within 5\%) in most of the cases predict correctly non-planarity of the enol tautomer. Taking into account the prediction of the relative stability of the tautomers HF with 6-31G**, 6-311++ $\mathrm{G}^{* *}$ and Dunning/Huzinaga full double zeta basis sets with addition of polarization and diffuse functions seems suitable choice for calculations of the tautomerism in $\mathbf{1}$.

The pure (OLYP) and hybrid density functionals like (B3LYP and B3PW91) describe very well the bond lengths, but fails in the prediction of the dihedral angle and the relative stability of the tautomers.

The deviations in the bond lengths description with LC-BLYP functional are relatively large, but it describes correctly the dihedral $\mathrm{C} 12-\mathrm{C} 1-\mathrm{N} 1-\mathrm{N} 2$ angle in the enol tautomer with $6-31+\mathrm{G}^{*}, 6-$ $31+G^{* *}$ and $6-31++G^{* *}$ basis sets; and slightly overestimate with
6-311 $++\mathrm{G}^{* *}$, Dunning's correlation consistent basis sets and when using TZVP basis set. Among them only with $6-31+\mathrm{G}^{* *}$ basis set predominance (although underestimated) of the enol tautomer is predicted.

The double hybrid functionals B2PLYP and mPW2PLYP give most accurate bond length descriptions and with Pople style basis sets with added diffuse functions $\left(6-31+G^{*}, 6-31+G^{* *}, 6-31++G^{* *}\right.$ and 6-311 $\left.++\mathrm{G}^{* *}\right)$ and TZVP and QZVP basis sets give reasonable value for the $\mathrm{C} 12-\mathrm{C} 1-\mathrm{N} 1-\mathrm{N} 2$ angle. Unfortunately with above mentioned basis sets the predicted relative stability of the tautomers is wrong, while with D95 $++^{* *}$ the accurately estimated relative energy is related to planar structure. In spite of substantially larger computational costs and predicted planarity, taking into account the importance of the accurate description of the position of the tautomeric equilibrium, the double hybrid functionals with D95++** basis set could be used as an alternative of the HF calculations.

\section{Acknowledgment}

The authors thank the Bulgarian National Science Fund (Projects TK-X-1716 and RNF01/0110), the SCOPES program of the Swiss National Science Foundation and FriMat for generous funding.

\section{Appendix. Supplementary data}

The crystallographic data for the products of $2,3,1$ NMe and 10Me were deposited at the Cambridge Crystallographic Data Centre and allocated the deposition numbers CCDC 810703, CCDC 810702 , CCDC 810700 and CCDC 810701, respectively. Copies of the data can be obtained, free of charge, on application to CCDC, 12 Union Road, Cambridge CB2 1EZ, UK; tel: +44 1223 762910; fax: +44 1223 336033; e-mail: deposit@ccdc.cam.ac.uk; http://www. ccdc.cam.ac.uk/deposit. Supplementary data associated with this article can be found in the online version, at doi:10.1016/j.dyepig. 2011.06.026.

\section{References}

[1] Sheikhshoaie I, Fabian WMF. Theoretical insights into material properties of Schiff bases and related azo compounds. Curr Org Chem 2009;13:147-71.

[2] Greenwood JR, Calkins D, Sullivan AP, Shelley JC. Towards the comprehensive, rapid, and accurate prediction of the favorable tautomeric states of drug-like molecules in aqueous solution. J Comput Aided Mol Des 2010;24:591-604. 
[3] Zincke T, Bindewald H. Ueber Phenylhydrazinderivate des $\alpha$ - und $\beta$-Naphtochinons. Identität des $\alpha$-Derivats mit dem Azoderivat des $\alpha$-Naphtols. Ber Dtsch Chem Ges 1884;17:3026-33.

[4] (a) Zollinger H. Color chemistry: syntheses, properties \& applications of organic dyes \& pigments. Weinheim: VCH; 1991;

(b) Gordon PF, Gregory P. Organic chemistry in colour. Berlin: SpringerVerlag 1983.

[5] Joshi H, Kamounah FS, van der Zwan G, Gooijer C, Antonov L. Temperature dependent absorption spectroscopy of some tautomeric azo dyes and Schiff bases. J Chem Soc Perkin Trans 2001;2(12):2303-8.

[6] Nedeltcheva D, Antonov L, Lycka A, Damyanova B, Popov S. Chemometric models for quantitative analysis of tautomeric Schiff bases and azo dyes. Curr Org Chem 2009;13:217-40.

[7] Kleinpeter E. Recent advances in studying tautomerism in solution and in solid state. Adv Mol Struct Res 2000;6:97-129.

[8] Antonov L, Nedeltcheva D. Resolution of UV-VIS absorption bands and quantitative analysis. Chem Soc Rev 2000;29:217-27. and the references cited therein.

[9] Antonov L, Kawauchi S, Satoh M, Komiyama J. Ab initio modeling the solvent influence on the azo-hydrazone tautomerism. Dyes Pigments 1999;40:163-70.

[10] Antonov L, Deneva V, Simeonov S, Kurteva V, Nedeltcheva D, Wirz ]. Exploiting tautomerism for switching and signaling. Angew Chem Int Ed 2009;48:7875-8.

[11] Das P, Biswas AN, Neogi DN, Bhawmick R, Bandyopadhyay P. (E)-1-[2-(Benzylsulfanyl)phenyldiazenyl]-4-methoxynaphthalene. Acta Cryst 2006;E62: 05536-8.

[12] (a) Morley J. Theoretical calculations of the structure of a donor-acceptor stilbene azobenzene and related molecules. J Mol Struct (Theochem) 1995;340:45-50; (b) Fabian WMF, Antonov L, Nedeltcheva D, Kamounah FS, Taylor PJ. Tautomerism in hydroxynaphthaldehyde anils and azo analogues: a combined experimental and computational study. J Phys Chem 2004;108:7603-12.

[13] Grimme S. Seemingly simple stereoelectronic effects in alkane isomers and the implications for Kohn-Sham density functional theory. Angew Chem Int Ed 2006;45:4460-4.

[14] Nedeltcheva D, Kurteva V, Damyanova B, Popov S. Gas-phase tautomerism in 1-phenylazonaphthalene-4-ol: verification of the responses of individual tautomers. Rapid Commun Mass Spectrom 2009;23:1727-34.
[15] Hahn WE, Weglewski J. Synthesis of aminoalcohols IX. Derivatives of 2Aminomethyl-4-phanylazo-naphthol-1. Acta Chimica 1966;11:67-74.

[16] Cosier J, Glazer AM. A nitrogen-gas-stream cryostat for general X-ray diffraction studies. J Appl Crystallogr 1986;19:105-7.

[17] Blanc E, Schwarzenbach D, Flack HD. The evaluation of transmission factors and their first derivatives with respect to crystal shape parameters. J Appl Crystallogr 1991;24:1035-41.

[18] Burla MC, Caliandro R, Camalli M, Carrozzini B, Cascarano GL, De Caro L, et al. SIR2004: an improved tool for crystal structure determination and refinement. J Appl Crystallogr 2005;38:381-8.

[19] Sheldrick GM. SHELX-97, program for crystal struture refinement, University of Göttingen 1997.

[20] Iikura H, Tsuneda T, Yanai T, Hirao K. A long-range correction scheme for generalized-gradient-approximation exchange functionals. J Chem Phys 2001; 115:3540-4.

[21] Grimme S. Semiempirical hybrid density functional with perturbative secondorder correlation. J Chem Phys 2006;124:034108.

[22] Schwabe T, Grimme S. Towards chemical accuracy for the thermodynamics of large molecules: new hybrid density functionals including non-local correlation effects. Phys Chem Chem Phys 2006;8:4398.

[23] Schaefer A, Huber C, Ahlrichs R. Fully optimized contracted Gaussian basis sets of triple zeta valence quality for atoms Li to Kr. J Chem Phys 1994;100: 5829-35.

[24] Weigend F, Ahlrichs R. Balanced basis sets of split valence, triple zeta valence and quadruple zeta valence quality for $\mathrm{H}$ to $\mathrm{Rn}$ : design and assessment of accuracy. Phys Chem Chem Phys 2005;7:3297-305.

[25] Frisch MJ, et al. Gaussian 09, revision A.02. Wallingford CT: Gaussian, Inc; 2009.

[26] Gilli P, Pretto L, Bertolasi V, Gilli G. Predicting hydrogen-bond strengths from acid-base molecular properties. The $\mathrm{pK}(\mathrm{a})$ slide rule: toward the solution of a long-lasting problem. Acc Chem Res 2009;42:33-44.

[27] Kelemen J, Kormany G, Rihs G. Azo-hydrazone tautomerism in azo dyes. III. The tautomeric structure of 1-(4'-nitrophenylazo)-2-naphthylamine from crystal structure determination. Dyes Pigments 1982;3:249-71.

[28] Harada J, Ogawa K, Tomoda S. Molecular motion and conformational interconversion of azobenzenes in crystals as studied by X-ray diffraction. Acta Cryst 1997;B53:662-72. 